\title{
Concurrent Solution of WATC Scheduling with WPPW Due Date Assignment for Environmentally Weighted Customers, Jobs and Services Using SA and its Hybrid
}

\author{
Halil Ibrahim Demir ${ }^{1}$, Caner Erden ${ }^{1}$, Abdullah Hulusi Kökçam ${ }^{1}$, and Ozer Uygun ${ }^{1}$ \\ ${ }^{1}$ Sakarya University, Industrial Engineering Department, Sakarya, Turkey
}

\begin{tabular}{l} 
Article Info \\
\hline Article history: \\
Received Sept 01, 2018 \\
Revised Oct 20, 2018 \\
Accepted Dec 20, 2018 \\
\hline Keyword: \\
Environmental Due-Date \\
Assignment \\
Environmental Scheduling \\
Simulated Annealing, Hybrid \\
Simulated Annealing \\
\hline
\end{tabular}

\begin{abstract}
After industrial revolution environmental problems increased drastically. Air, water and soil pollution became a serious threat for the mankind. In order to overcome this threat everyone should take responsibility and try to preserve environment as much as possible. Environmentally conscious actions, people, law and foundations should be supported. When it came to determining due dates and scheduling, one of the important criteria should be the supporting the environment. In this study environmentally conscious customers, jobs, and services are rewarded, on the other hand unconscious customers, jobs, and services are penalized, while determining due dates and schedules. Simulated annealing and its hybrid with random search are applied to get environmentally better due dates and schedules.
\end{abstract}

\section{Corresponding Author:}

First Author,

Department of Industrial Engineering,

Sakarya University,

Esentepe Campus, Serdivan/Sakarya/Turkey.

Email: hidemir@sakarya.edu.tr

\section{Introduction}

Energy demands of developing countries has been increased rapidly with the globalization and technology developments [1]. Almost half of the world's total energy is consumed by manufacturing industries [2]. Relatively rapid increase of energy consumption rates triggers global warming and cause serious environmental problems. Due to environmental issues, organizations and manufacturing systems are encouraged for research and development (R\&D) over renewable energy sources such as sunlight, wind, flowing water, the earth's internal heat and green [3]. Sustainable economic development may be real if manufacturing become environmental friendly [4], [5].

For the same purpose, organizations have also researched intensively in the field of job scheduling because the interest on environmental friendly production is increased. Job scheduling deals with the assignment of the jobs in which to be done in the process from the raw material to the finished product to the machines. An evaluation of job shop dispatching rules was conducted in paper [6]. Thus, it is ensured that the customer which has more importance for the manufacturer has a priority. In a typical scheduling model, weight of customers are determined with the quantities in the order list. In this study, a distinction was made between the customers regarding their consciousness in environmental friendly production. It is aimed to encourage the manufacturers who produces environmental friendly products by scheduling them firstly. A substantial energy have been consumed on inefficient processes such as cooling, heating, pressing etc. in all over the Europe [7]. Therefore, the improvements made on production methods affects the sustainability of production at a large scale. 
In this study, the scheduling problem and the due date assignment problem are integrated to make production planning considering environmental issues. Job shops consisting of more than one job, and machine are studied in the scheduling problem. It is assumed that there is single route for each job. In due date assignment phase, environmental friendly customers are also considered, which are manufacturing products in a proper way to protect environment. Each job in an organization can be classified as a customer. The weighting of the jobs is not done by only considering the single criteria as it is done in the traditional scheduling problems. Also, other criteria are used to calculate weights for a job. In the literature, there are many studies which have given weights to the jobs according to different criteria. In 2000, Agnetis et al. carried out the weighting of the jobs according to the amount of work in the workshop. Besides, they have tried to minimize the completion times and the number of jobs delayed [8].

Furthermore, integrated process planning and scheduling problem (IPPS) is also a new trend topic in terms of decreasing energy consumption in a manufacturing process. Zhang et al. have conducted a machine scheduling system to save energy in manufacturing system [9]. In this study, the energy consumption of machines and equipment is modeled as Therblig base in the process of manufacturing. In IPPS, process planning, and scheduling functions are integrated with alternative process plans. It has resulted in higher efficiency in energy saving. First study on IPPS was made by Wilhelm and Shin. They conducted a study to use production sources in an efficient way using alternative operations in 1985 [10]. Before studies on IPPS, process planning, and scheduling have been taken separately like a one function. Only scheduling functions are classified as NP-Hard problem. So, it is almost impossible to find optimal results in real applications for IPPS [11]. That is why, there are many studies on IPPS using meta-heuristic approaches such as genetic algorithm [12]-[16], simulated annealing [12], taboo search [17], particle swarm optimization [18], [19], agent-based [20], [21] and ant colony optimization [22].

Other integration problem is the scheduling with due date assignment problem (SWDDA). Basic principle of a just-in-time (JIT) philosophy is to minimize the unnecessary costs in production and to ensure a job is to be completed on its time. It is advised to finish products as close as possible to the due date in JIT. If an organization can schedule its production on the due dates which are reasonable, it will have optimum capacity planning. Using resources in an efficient way, may prevent labor cost and unnecessary energy consumption. The completion time of jobs before their due date could lead to an increase in energy costs and a decrease in customer satisfaction and customer loss. Integrated systems are determined by considering the scheduling and due date assignment together to avoid inefficient production plan. Some earlier studies reported that it was possible to find the optimal due dates and optimal sequences of jobs using different heuristic algorithms [8] [16]. The objective of these studies is to minimize the cost related to due date assignment and scheduling function. Besides, some recent studies on SWDDA can be listed as; [17]-[36].

The remainder of the paper is organized as follows. In Section 2 modelling integrated production plan is discussed and the data used for the problem is described. Results of the schedules are given in Section 3. Section 4 includes conclusions and the discussing part of the study.

\section{Materials and Method}

Random Search (RS), Simulated Annealing (SA) and their hybrid is used in this study. Ordinary solution indicates the initially generated random solution.

Random Search (RS): RS uses new random solutions at each iteration. It has the advantage of fast improvement in the beginning of the iterations. Later rate of improvement quickly reduces.

Simulated Annealing (SA): SA used to solve large scale optimization problems, which was developed by Kirkpatrick et al. [52] in 1983. It is used in many problems in numerous discipline especially global extremum is searched within the many local extrema [53].

Random and Simulated Annealing (RS/SA): Random search was combined with SA and this hybrid method is utilized. Initial 5\% of iterations are made with random search and rest of the iterations are made with SA. It is aimed to take advantage of wide search capability of random search, and more focused search capability of SA to obtain better solutions. Random search scans the solution space to faster and better only at the very beginning. Later SA focuses this solutions to get better ones.

As scheduling rules WATC (Weighted Apparent Tardiness Cost), ATC (Apparent Tardiness Cost) and SIRO (Service in random order) rules are utilized throughout the study. As due date assignment rules WPPW (Weighted process plus wait), PPW (Process plus wait) and RDM (Random) rules are applied. Rules for Scheduling and Due date assignment are explained in Appendix A and B respectively. 
For the solution of the integrated problem a program is coded in C++ which performs Random Search, Simulated Annealing and Hybrid Simulated Annealing algorithms. Initially jobs are given proper due-dates by using WPPW, PPW or RND due-date assignment techniques and later jobs are scheduled according to WATC, ATC or SIRO rules and performance of the solution is calculated. After that in every iteration performance measure is tried to be improved by using RS, SA or RS/SA techniques.

Four different integration levels are utilized, which are SIRO-RDM, WATC-RDM, SIRO-WPPW, WATCWPPW, and for the full integration level the combination ATC-PPW is also tested for unweighted customer case.

SIRO-RDM: There is no integration in this level. Jobs are scheduled according to service in random order rule and due dates are assigned randomly.

WATC-RDM: WATC scheduling rule is integrated with process plan selection. Due dates are still randomly assigned.

SIRO-WPPW: WPPW weighted due date assignment rule is used to determine due dates in this combination. On the other hand scheduling is made with service in random order rule.

WATC-WPPW: Process planning is integrated with WATC weighted scheduling and WPPW weighted due date assignment in this integration level. This s the best level and full integration level of the problem. Here weights of the customers were also taken into account.

ATC-PPW: This level is same as the WATC-WPPW method except customers are not weighted with their environmental manner. This combination is given to compare solutions, thus observing the effect of weighting customers.

Eight different shop floors with varying size are studied. Smallest shop floor has 5 machines and 25 jobs. There are 5 operations in each route. Processing time of each operation practically changes in between 1 and 30 minutes according to formula $\left[\left(12+z^{*} 6\right)\right]$.

Largest shop floor has 10 machines, 200 jobs and same number of operations in each route as in smallest shop floor. Processing times are same as in other shop floors. Characteristics of each shop floor are listed at Table 1.

Table 1. Shop floors

\begin{tabular}{lcccccccc}
\hline Shop Floor & 1 & 2 & 3 & 4 & 5 & 6 & 7 & 8 \\
\# of machines & 5 & 5 & 5 & 5 & 10 & 10 & 10 & 10 \\
\# of Jobs & 25 & 50 & 75 & 100 & 125 & 150 & 175 & 200 \\
$\begin{array}{l}\text { Processing Times } \\
\text { \# of op. per job }\end{array}$ & \multicolumn{8}{c}{$\left[\begin{array}{l}(12+\mathrm{z} * 6)\rfloor \\
\hline\end{array}\right.$}
\end{tabular}

\section{Results}

Everyone must take responsibility to preserve the environment as our world has limited resources. In this study customers are prioritized in terms of their attitudes towards preserving the environment. Comparison of twenty solution combinations for all the shop floors are given in Table 2. Results of weighted and unweighted fully integrated level of all shop floors are given in Fig. 1-8. Obtained results indicate that weighting the customers according to their environmental consciousness has a positive effect on schedule in all eight shop floors. CPU time of programs are under one second for small shop floors and under one minute for largest shop floors. 


\begin{tabular}{|c|c|c|c|c|c|c|c|c|c|c|c|c|c|c|c|c|c|c|c|c|c|c|c|c|c|}
\hline \multirow{2}{*}{$\begin{array}{l}\text { Level of } \\
\text { Integration } \\
\end{array}$} & \multirow{2}{*}{ Approaches } & \multicolumn{3}{|c|}{ Shop Floor 1} & \multicolumn{3}{|c|}{ Shop Floor 2} & \multicolumn{3}{|c|}{ Shop Floor 3} & \multicolumn{3}{|c|}{ Shop Floor 4} & \multicolumn{3}{|c|}{ Shop Floor 5} & \multicolumn{3}{|c|}{ Shop Floor 6} & \multicolumn{3}{|c|}{ Shop Floor 7} & \multicolumn{3}{|c|}{ Shop Floor 8} \\
\hline & & Best & Avg. & Worst & Best & Avg & Worst & Best & Avg. & Worst & Best & Avg. & Worst & Best & Avg. & Worst & Best & Avg. & Worst & Best & Avg. & Worst & Best & Avg. & Worst \\
\hline \multirow{4}{*}{ SIRO-RDM } & $\mathrm{OS}$ & 287 & 287 & 287 & 848 & 848 & 848 & 1689 & 1689 & 1689 & 3028 & 3028 & 3028 & 2617 & 2617 & 2617 & 3704 & 3704 & 3704 & 4730 & 4730 & 4730 & 6344 & 6344 & 6344 \\
\hline & RS & 258 & 259 & 260 & 723 & 731 & 737 & 1491 & 1516 & 1525 & 2722 & 2759 & 2787 & 2242 & 2286 & 2306 & 3171 & 3260 & 3291 & 4194 & 4272 & 4308 & 5658 & 5762 & 5805 \\
\hline & SA & 263 & 266 & 269 & 810 & 824 & 830 & 1613 & 1662 & 1680 & 2956 & 2986 & 3013 & 2469 & 2536 & 2560 & 3544 & 3572 & 3591 & 4557 & 4603 & 4626 & 6133 & 6184 & 6225 \\
\hline & $\mathrm{RS} / \mathrm{S}$ & 258 & 267 & 270 & 796 & 818 & 829 & 1597 & 1650 & 1673 & 2922 & 2978 & 2998 & 2512 & 2536 & 2555 & 3452 & 3557 & 3590 & 4536 & 4579 & 4611 & 6155 & 6179 & 6210 \\
\hline \multirow{4}{*}{ WATC-RDM } & $\mathrm{OS}$ & 246 & 246 & 246 & 645 & 645 & 645 & 1221 & 1221 & 1221 & 2203 & 2203 & 2203 & 1916 & 1916 & 1916 & 2649 & 2649 & 2649 & 3299 & 3299 & 3299 & 4544 & 4544 & 4544 \\
\hline & RS & 257 & 264 & 270 & 656 & 688 & 712 & 1271 & 1288 & 1305 & 2233 & 2256 & 2274 & 1923 & 1981 & 2014 & 2623 & 2697 & 2736 & 3326 & 3385 & 3423 & 4589 & 4629 & 4667 \\
\hline & SA & 246 & 247 & 250 & 645 & 651 & 657 & 1221 & 1235 & 1246 & 2203 & 2217 & 2226 & 1916 & 1946 & 1978 & 2649 & 2658 & 2672 & 3299 & 3313 & 3332 & 4544 & 4570 & 4598 \\
\hline & $\begin{array}{l}\mathrm{RS} / \mathrm{SA} \\
\end{array}$ & 246 & 247 & 250 & 645 & 651 & 657 & 1221 & 1235 & 1246 & 2203 & 2217 & 2226 & 1916 & 1946 & 1978 & 2649 & 2658 & 2672 & 3299 & 3313 & 3332 & 4544 & 4570 & 4598 \\
\hline \multirow{4}{*}{ SIRO-WPPW } & $\mathrm{OS}$ & 275 & 275 & 275 & 907 & 907 & 907 & 1771 & 1771 & 1771 & 3031 & 3031 & 3031 & 2676 & 2676 & 2676 & 3638 & 3638 & 3638 & 4724 & 4724 & 4724 & 6258 & 6258 & 6258 \\
\hline & RS & 258 & 270 & 275 & 812 & 824 & 835 & 1622 & 1663 & 1691 & 2831 & 2934 & 2973 & 2420 & 2462 & 2507 & 3439 & 3479 & 3520 & 4385 & 4464 & 4513 & 5894 & 6003 & 6082 \\
\hline & SA & 265 & 273 & 276 & 789 & 804 & 812 & 1658 & 1668 & 1674 & 2891 & 2927 & 2945 & 2379 & 2437 & 2469 & 3440 & 3487 & 3517 & 4278 & 4409 & 4473 & 5913 & 5949 & 5986 \\
\hline & $\mathrm{RS} / \mathrm{S}$ & 254 & 266 & 274 & 773 & 800 & 811 & 1567 & 1647 & 1684 & 2861 & 2932 & 2964 & 2429 & 2453 & 2465 & 3388 & 3492 & 3529 & 4439 & 4485 & 4516 & 5979 & 6047 & 6083 \\
\hline \multirow{4}{*}{ WATC-WPPW } & $\mathrm{OS}$ & 246 & 246 & 246 & 640 & 640 & 640 & 1217 & 1217 & 1217 & 2174 & 2174 & 2174 & 1821 & 1821 & 1821 & 2537 & 2537 & 2537 & 3133 & 3133 & 3133 & 4401 & 4401 & 4401 \\
\hline & $\mathrm{RS}$ & 221 & 235 & 241 & 613 & 626 & 639 & 1180 & 1199 & 1217 & 2093 & 2139 & 2169 & 1699 & 1754 & 1818 & 2365 & 2438 & 2532 & 2921 & 3019 & 3133 & 4164 & 4280 & 4401 \\
\hline & SA & 221 & 236 & 246 & 613 & 626 & 639 & 1180 & 1203 & 1222 & 2093 & 2139 & 2169 & 1699 & 1767 & 1835 & 2365 & 2455 & 2537 & 2921 & 3057 & 3141 & 4164 & 4300 & 4402 \\
\hline & $\mathrm{RS} / \mathrm{S}$ & 221 & 237 & 246 & 613 & 631 & 647 & 1180 & 1199 & 1217 & 2093 & 2139 & 2169 & 1699 & 1754 & 1818 & 2365 & 2447 & 2535 & 2921 & 3038 & 3138 & 4164 & 4300 & 4402 \\
\hline \multirow{4}{*}{ ATC-PPW } & $\mathrm{OS}$ & 253 & 253 & 253 & 733 & 733 & 733 & 1459 & 1459 & 1459 & 2574 & 2574 & 2574 & 2120 & 2120 & 2120 & 2913 & 2913 & 2913 & 3766 & 3766 & 3766 & 5119 & 5119 & 5119 \\
\hline & RS & 250 & 255 & 258 & 707 & 728 & 743 & 1423 & 1451 & 1466 & 2533 & 2560 & 2580 & 2080 & 2114 & 2166 & 2837 & 2893 & 2962 & 3693 & 3755 & 3830 & 5015 & 5088 & 5170 \\
\hline & SA & 250 & 262 & 283 & 707 & 728 & 743 & 1423 & 1462 & 1513 & 2538 & 2576 & 2636 & 2080 & 2132 & 2213 & 2837 & 2909 & 2977 & 3693 & 3778 & 3885 & 5015 & 5109 & 5208 \\
\hline & $\begin{array}{l}\mathrm{RS} / \mathrm{SA} \\
\end{array}$ & 251 & 256 & 260 & 707 & 739 & 768 & 1423 & 1468 & 1515 & 2533 & 2592 & 2655 & 2080 & 2148 & 2232 & 2837 & 2932 & 3028 & 3693 & 3793 & 3885 & 5015 & 5143 & 5260 \\
\hline
\end{tabular}

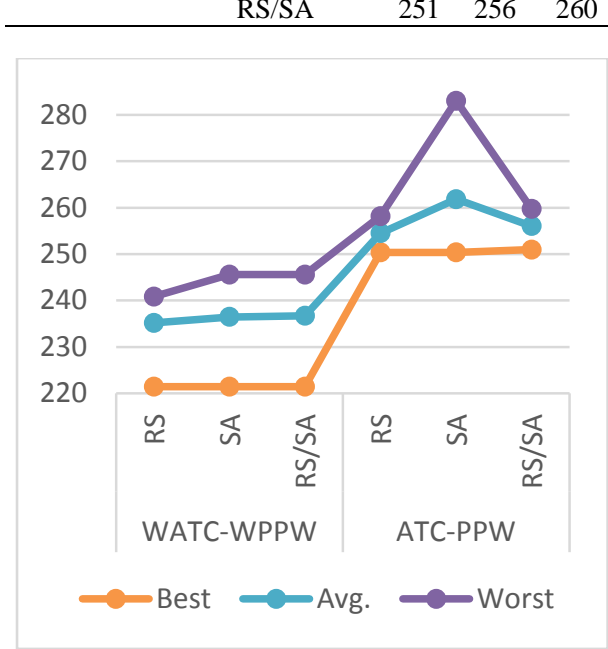

Figure 1. Result of shop floor 1 (25x5)

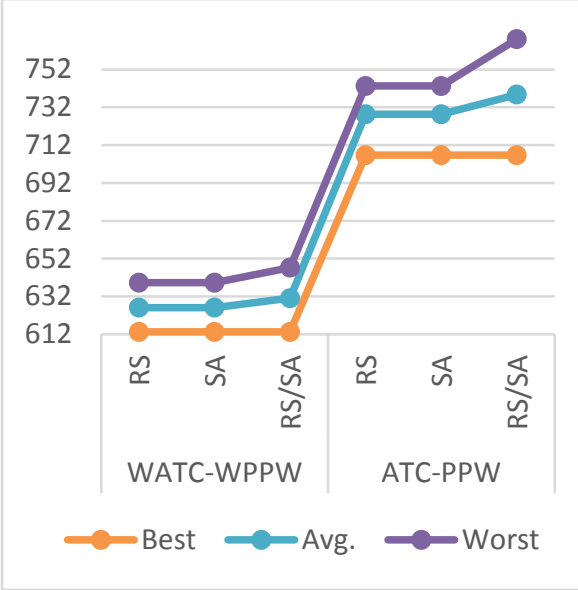

Figure 2. Result of shop floor 2 (50x5)

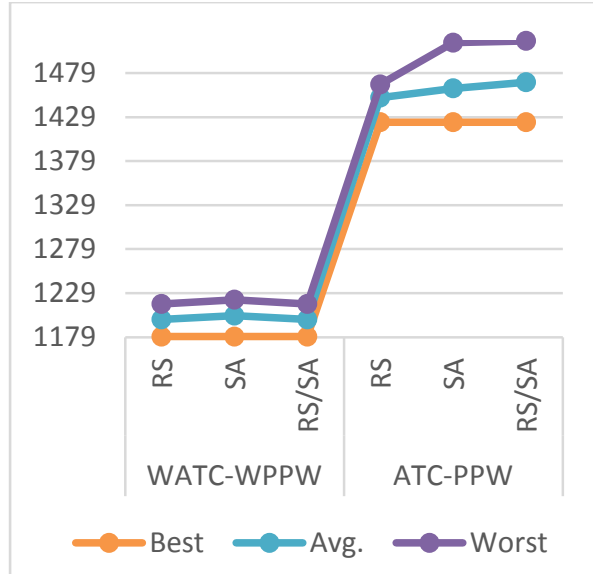

Figure 3. Result of shop floor 3 (75x5)

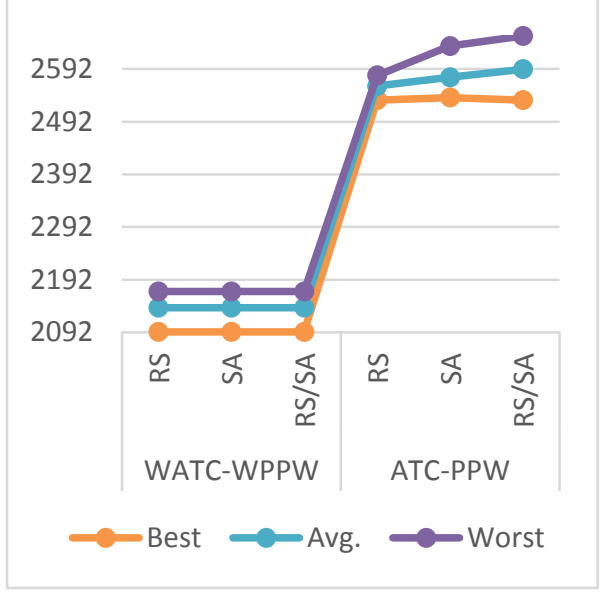

Figure 4. Result of shop floor 4 (100x5) 
Although as integration levels increases better schedules are obtained, weighting the customers are much more improved the solution. Random Search, Simulated Annealing and their hybrid gave close results. Ordinary solutions are worst compared the search methods. As they are not given in figures for readability.

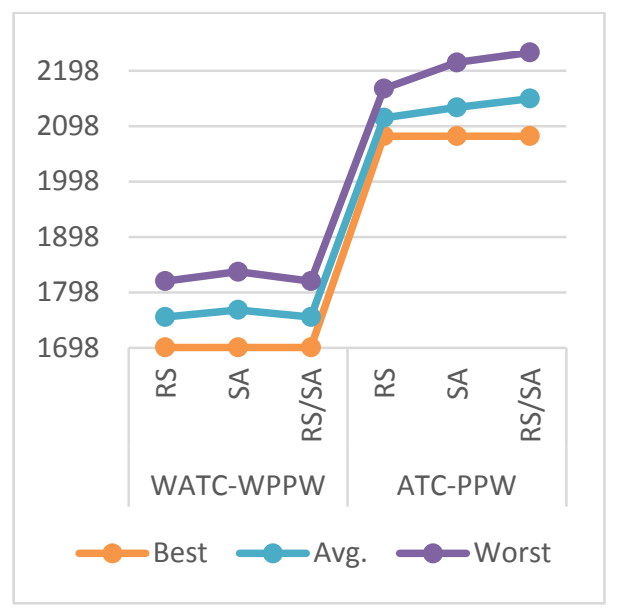

Figure 5. Result of shop floor $5(125 \times 10)$

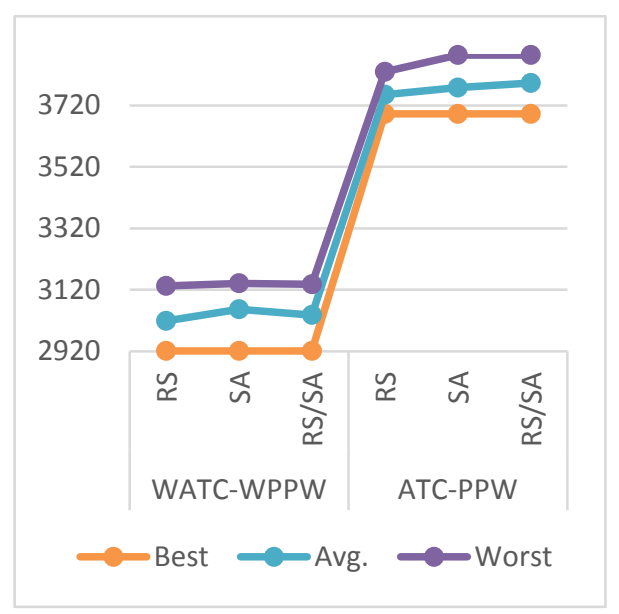

Figure 7. Result of shop floor $7(175 \times 10)$

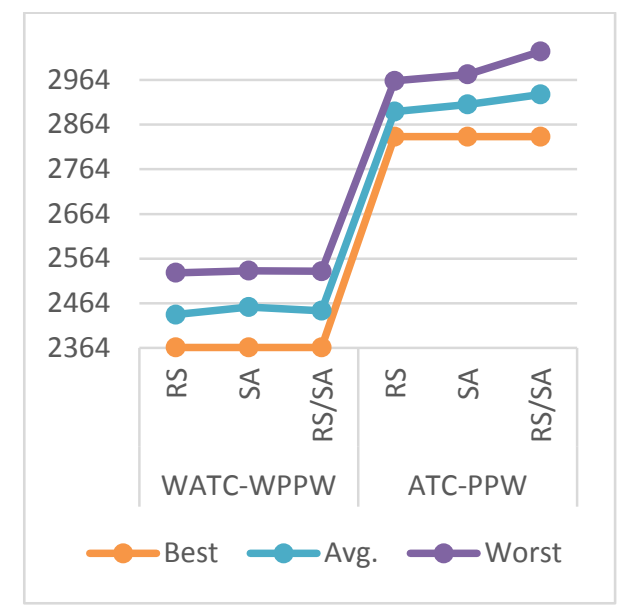

Figure 6. Result of shop floor $6(150 \times 10)$

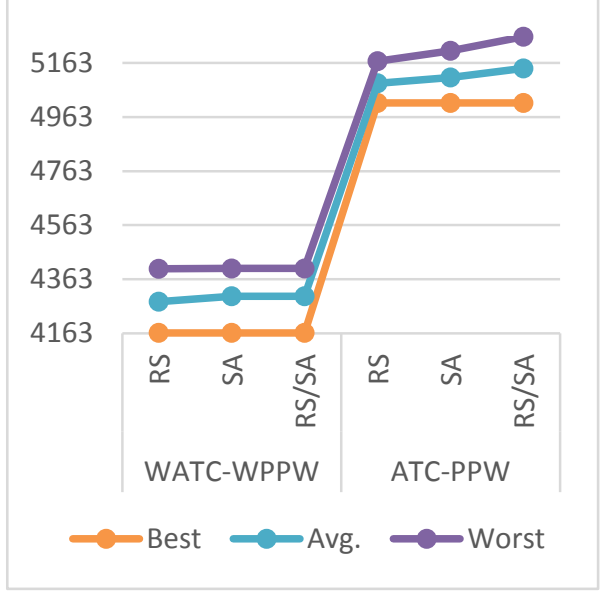

Figure 8. Result of shop floor 8 (200x10)

It has been seen that the range of change is decreases as the integration level increases. Thus, more integrated solutions gave similar results independently of method used. It is also noteworthy that RS has minimum values amongst worst solutions.

\section{Conclusions}

In this study scheduling with due-date assignment problem is studied for environmentally weighted customers. Step by step scheduling and due-date assignment functions are integrated. Initially SIRO scheduling and RDM due-date assignment combinations are tested and as expected this level found as the poorest integration level. Later WATC dispatching is introduced to the problem and integrating scheduling with the problem is found useful. After that WPPW is integrated with the problem but this time jobs or services are scheduled according to SIRO rule. Finally WATC scheduling and WPPW due-date assignment rules are integrated and full integrated level is tested and found as the best level of integration.

For the fully integrated level ATC scheduling and PPW due-date assignment integration is also tested where weights of the customers are not taken into account. WATC-WPPW integration is found much better compared to the ATC-PPW integration levels and results can be found in the Section 3 where the results are discussed. According to the results it is much better to schedule customers according to environmentally given weights. 
If it is desired to increase environmentally sensitive people, those customers should be rewarded, and those who are not sensitive should be punished. Jobs and services should be weighted according to environmental criteria to raise awareness for environment.

\section{Appendix A: Due-Date Assignment Rules}

WPPW (Weighted Process Plus Wait) $\rightarrow$ Due $=\mathrm{q}_{\mathrm{x}} * \mathrm{w}_{1}+\mathrm{w}_{2} * \mathrm{k}_{\mathrm{x}} * \mathrm{TPT}\left(\mathrm{w}_{1}, \mathrm{w}_{2}\right.$ is determined according to weights) $\mathrm{q}_{\mathrm{x}}=\mathrm{q}_{1}, \mathrm{q}_{2}$ or $\mathrm{q}_{3} \quad \mathrm{q}_{1}=0.5 * \mathrm{P}_{\text {avg }}, \mathrm{q}_{2}=\mathrm{P}_{\text {avg }}, \mathrm{q}_{3}=1.5 * \mathrm{P}_{\text {avg }}, \mathrm{k}_{\mathrm{x}}=1,2,3$

PPW (Process Plus wait) $\rightarrow$ Due $=\mathrm{q}_{\mathrm{x}}+\mathrm{k}_{\mathrm{x}} * \mathrm{TPT}$ where $\mathrm{q}_{\mathrm{x}}=\mathrm{q}_{1}, \mathrm{q}_{2}$ or $\mathrm{q}_{3} \mathrm{q}_{1}=0.5 * \mathrm{P}_{\text {avg }}, \mathrm{q}_{2}=\mathrm{P}_{\text {avg }}, \mathrm{q}_{3}=1.5^{*} \mathrm{P}_{\text {avg }}$, $\mathrm{k}_{\mathrm{x}}=1,2,3$

RDM (Random Due Assignment $) \rightarrow$ Due $=\mathrm{N} \sim\left(3 * \mathrm{P}_{\text {avg }},\left(\mathrm{P}_{\text {avg }}\right)^{2}\right)$

TPT $=$ Total Processing Time

$\mathrm{P}_{\mathrm{avg}}=$ Mean processing time of all job waiting

Appendix B: Dispatching Rules

WATC (Weighted Apparent Tardiness Cost): It is a hybrid of MS (Minimum Slack First) and SPT (Shortest Processing Time First) dispatching rules where priority index is calculated as follows.

$\mathrm{I}_{\mathrm{j}}(\mathrm{t})=\mathrm{w}_{\mathrm{j}} / \mathrm{p}_{\mathrm{j}} * \exp \left(-\max \left(\mathrm{d}_{\mathrm{j}}-\mathrm{p}_{\mathrm{j}}-\mathrm{t}, 0\right) / \mathrm{K} * \mathrm{P}_{\mathrm{avg}}\right)$ where

$\mathrm{I}_{\mathrm{j}}(\mathrm{t})$ is priority index

$\mathrm{p}_{\mathrm{j}}$ is $\mathrm{j}^{\text {th }}$ job processing time

$\max \left(\mathrm{d}_{\mathrm{j}}-\mathrm{p}_{\mathrm{j}}-\mathrm{t}, 0\right)$ is $\mathrm{j}^{\text {th }}$ job slack

$\mathrm{K}$ is scaling parameter

$\mathrm{P}_{\mathrm{avg}}$ is average processing time of the jobs

ATC: (Apparent Tardiness Cost) According to ATC rule priority index is calculated as follows

$\mathrm{I}_{\mathrm{j}}(\mathrm{t})=1 / \mathrm{p}_{\mathrm{j}}^{*} \exp \left(-\max \left(\mathrm{d}_{\mathrm{j}}-\mathrm{p}_{\mathrm{j}} \mathrm{t}, 0\right) / \mathrm{K} * \mathrm{P}_{\text {avg }}\right)$

SIRO (Service in Random Order): A job among waiting jobs is selected randomly to be processed.

\section{References}

[1] "BP Statistical Review of World Energy," 06-Jan-2013. [Online]. Available: http://bp.com/statisticalreview. [Accessed: 14-Apr-2018].

[2] U. S. Briefing, "International Energy Outlook 2013," US Energy Information Administration, 2013.

[3] F. Iovane et al., "The incoming global technological and industrial revolution towards competitive sustainable manufacturing," CIRP ANNALS, vol. 57, pp. 641-659, 2007.

[4] S. R. Bull, "Renewable energy today and tomorrow," Proceedings of the IEEE, vol. 89, no. 8, pp. 12161226, 2001.

[5] E. Kandemir, N. S. Cetin, and S. Borekci, "A Comparison of Perturb \& Observe and Fuzzy-Logic Based MPPT Methods for Uniform Environment Conditions," Periodicals of Engineering and Natural Sciences (PEN), vol. 5, no. 1, pp. 16-23, Mar. 2017.

[6] C. H. Jones, "An Economic Evaluation of Job Shop Dispatching Rules," Management Science, vol. 20, no. 3, pp. 293-307, Nov. 1973.

[7] E. O'Driscoll and G. E. O'Donnell, "Industrial power and energy metering-a state-of-the-art review," Journal of Cleaner Production, vol. 41, pp. 53-64, 2013.

[8] A. Agnetis, P. B. Mirchandani, D. Pacciarelli, and A. Pacifici, "Nondominated schedules for a job-shop with two competing users," Computational \& Mathematical Organization Theory, vol. 6, no. 2, pp. 191-217, 2000.

[9] Z. Zhang, R. Tang, T. Peng, L. Tao, and S. Jia, "A method for minimizing the energy consumption of machining system: integration of process planning and scheduling," Journal of cleaner production, vol. 137, pp. 1647-1662, 2016.

[10] X. Li, L. Gao, X. Shao, C. Zhang, and C. Wang, "Mathematical modeling and evolutionary algorithmbased approach for integrated process planning and scheduling," Computers \& Operations Research, vol. 37, no. 4, pp. 656-667, 2010.

[11] M. R. Amin-Naseri and A. J. Afshari, "A hybrid genetic algorithm for integrated process planning and scheduling problem with precedence constraints," The International Journal of Advanced Manufacturing Technology, vol. 59, no. 1-4, pp. 273-287, 2012.

[12] X. Shao, X. Li, L. Gao, and C. Zhang, "Integration of process planning and scheduling - a modified genetic algorithm-based approach," Computers \& Operations Research, vol. 36, no. 6, pp. 2082-2096, 2009. 
[13] Q. Lihong and L. Shengping, “An improved genetic algorithm for integrated process planning and scheduling," The International Journal of Advanced Manufacturing Technology, vol. 58, no. 5-8, pp. 727-740, 2012.

[14] S. Liu and L. Qu, "A new field balancing method of rotor systems based on holospectrum and genetic algorithm," Applied Soft Computing, vol. 8, no. 1, pp. 446-455, 2008.

[15] X. Li, L. Gao, and X. Shao, "An active learning genetic algorithm for integrated process planning and scheduling," Expert Systems with Applications, vol. 39, no. 8, pp. 6683-6691, 2012.

[16] C. Moon and Y. Seo, "Evolutionary algorithm for advanced process planning and scheduling in a multiplant," Computers \& Industrial Engineering, vol. 48, no. 2, pp. 311-325, 2005.

[17] S. K. Shukla, M. K. Tiwari, and Y. J. Son, "Bidding-based multi-agent system for integrated process planning and scheduling: a data-mining and hybrid tabu-SA algorithm-oriented approach," The International Journal of Advanced Manufacturing Technology, vol. 38, no. 1-2, p. 163, 2008.

[18] Y. W. Guo, W. D. Li, A. R. Mileham, and G. W. Owen, "Applications of particle swarm optimisation in integrated process planning and scheduling," Robotics and Computer-Integrated Manufacturing, vol. 25, no. 2, pp. 280-288, 2009.

[19] Y. W. Guo, W. D. Li, A. R. Mileham, and G. W. Owen, "Optimisation of integrated process planning and scheduling using a particle swarm optimisation approach," International Journal of Production Research, vol. 47, no. 14, pp. 3775-3796, 2009.

[20] X. Li, C. Zhang, L. Gao, W. Li, and X. Shao, "An agent-based approach for integrated process planning and scheduling," Expert Systems with Applications, vol. 37, no. 2, pp. 1256-1264, 2010.

[21] T. N. Wong, C. W. Leung, K. L. Mak, and R. Y. K. Fung, "An agent-based negotiation approach to integrate process planning and scheduling," International journal of production research, vol. 44, no. 7, pp. 1331-1351, 2006.

[22] C. W. Leung, T. N. Wong, K.-L. Mak, and R. Y. Fung, "Integrated process planning and scheduling by an agent-based ant colony optimization," Computers \& Industrial Engineering, vol. 59, no. 1, pp. 166$180,2010$.

[23] H. Luss and M. B. Rosenwein, "A due date assignment algorithm for multiproduct manufacturing facilities," European Journal of Operational Research, vol. 65, no. 2, pp. 187-198, 1993.

[24] T. Yang, Z. He, and K. K. Cho, "An effective heuristic method for generalized job shop scheduling with due dates," Computers \& Industrial Engineering, vol. 26, no. 4, pp. 647-660, 1994.

[25] X. Cai, V. Y. S. Lum, and J. M. T. Chan, "Scheduling about a common due date with kob-dependent asymmetric earliness and tardiness penalties," European journal of operational research, vol. 98, no. 1, pp. 154-168, 1997.

[26] D. Chen, S. Li, and G. Tang, "Single machine scheduling with common due date assignment in a group technology environment," Mathematical and Computer Modelling, vol. 25, no. 3, pp. 81-90, 1997.

[27] M. Y. Kovalyov, "Batch scheduling and common due date assignment problem: An NP-hard case," Discrete Applied Mathematics, vol. 80, no. 2-3, pp. 251-254, 1997.

[28] V. Gordon and W. Kubiak, "Single machine scheduling with release and due date assignment to minimize the weighted number of late jobs," Information Processing Letters, vol. 68, no. 3, pp. 153$159,1998$.

[29] G. I. Adamopoulos and C. P. Pappis, "Scheduling under a common due-data on parallel unrelated machines," European Journal of Operational Research, vol. 105, no. 3, pp. 494-501, 1998.

[30] T. C. E. Cheng and M. Y. Kovalyov, "Complexity of parallel machine scheduling with processing-pluswait due dates to minimize maximum absolute lateness," European Journal of Operational Research, vol. 114, no. 2, pp. 403-410, 1999.

[31] V. S. Gordon and V. A. Strusevich, "Earliness penalties on a single machine subject to precedence constraints: SLK due date assignment," Computers \& Operations Research, vol. 26, no. 2, pp. 157-177, 1999.

[32] D. Biskup and H. Jahnke, "Common due date assignment for scheduling on a single machine with jointly reducible processing times," International Journal of Production Economics, vol. 69, no. 3, pp. 317-322, 2001.

[33] G. Mosheiov, "A common due-date assignment problem on parallel identical machines," Computers and Operations Research, vol. 28, no. 8, pp. 719-732, 2001. 
[34] J. N. D. Gupta, K. Krüger, V. Lauff, F. Werner, and Y. N. Sotskov, "Heuristics for hybrid flow shops with controllable processing times and assignable due dates," Computers and Operations Research, vol. 29, no. 10, pp. 1417-1439, 2002.

[35] X. Qi, G. Yu, and J. F. Bard, "Single machine scheduling with assignable due dates," Discrete Applied Mathematics, vol. 122, no. 1-3, pp. 211-233, 2002.

[36] V. S. Gordon, J.-M. Proth, and C. Chu, "Due date assignment and scheduling: Slk, TWK and other due date assignment models," Production Planning \& Control, vol. 13, no. 2, pp. 117-132, 2002.

[37] C. T. D. Ng Daniel, T. C. E. Cheng, M. Y. Kovalyov, and S. S. Lam, "Single machine scheduling with a variable common due date and resource-dependent processing times," Computers and Operations Research, vol. 30, no. 8, pp. 1173-1185, 2003.

[38] M. Birman and G. Mosheiov, "A note on a due-date assignment on a two-machine flow-shop," Computers and Operations Research, vol. 31, no. 3, pp. 473-480, 2004.

[39] V. Lauff and F. Werner, "Scheduling with common due date, earliness and tardiness penalties for multimachine problems: A survey," Mathematical and Computer Modelling, vol. 40, no. 5-6, pp. 637655, 2004.

[40] L. Min and W. Cheng, "Genetic algorithms for the optimal common due date assignment and the optimal scheduling policy in parallel machine earliness/tardiness scheduling problems," Robotics and Computer-Integrated Manufacturing, vol. 22, no. 4, pp. 279-287, 2006.

[41] G. Mosheiov and U. Yovel, "Minimizing weighted earliness-tardiness and due-date cost with unit processing-time jobs," European Journal of Operational Research, vol. 172, no. 2, pp. 528-544, 2006.

[42] J. B. Wang, "Single machine scheduling with common due date and controllable processing times," Applied Mathematics and Computation, vol. 174, no. 2, pp. 1245-1254, 2006.

[43] A. Baykasoğlu, M. Göçken, and Z. D. Unutmaz, "New approaches to due date assignment in job shops," European Journal of Operational Research, vol. 187, no. 1, pp. 31-45, 2008.

[44] Y. Xia, B. Chen, and J. Yue, "Job sequencing and due date assignment in a single machine shop with uncertain processing times," European Journal of Operational Research, vol. 184, no. 1, pp. 63-75, 2008.

[45] D. Shabtay, "Due date assignments and scheduling a single machine with a general earliness/tardiness cost function," Computers and Operations Research, vol. 35, no. 5, pp. 1539-1545, 2008.

[46] V. S. Gordon and V. A. Strusevich, "Single machine scheduling and due date assignment with positionally dependent processing times," European Journal of Operational Research, vol. 198, no. 1, pp. 57-62, 2009.

[47] H. Allaoua and I. Osmane, "Variable parameters lengths genetic algorithm for minimizing earlinesstardiness penalties of single machine scheduling with a common due date," Electronic Notes in Discrete Mathematics, vol. 36, no. C, pp. 471-478, 2010.

[48] N. Huynh Tuong and A. Soukhal, "Due dates assignment and JIT scheduling with equal-size jobs," European Journal of Operational Research, vol. 205, no. 2, pp. 280-289, 2010.

[49] Y. Yin, T. C. E. Cheng, D. Xu, and C.-C. Wu, "Common due date assignment and scheduling with a rate-modifying activity to minimize the due date, earliness, tardiness, holding, and batch delivery cost," Computers \& Industrial Engineering, vol. 63, no. 1, pp. 223-234, 2012.

[50] S. Li, C. T. Ng, and J. Yuan, "Scheduling deteriorating jobs with CON/SLK due date assignment on a single machine," International Journal of Production Economics, vol. 131, no. 2, pp. 747-751, 2011.

[51] V. Vinod and R. Sridharan, "Simulation modeling and analysis of due-date assignment methods and scheduling decision rules in a dynamic job shop production system," International Journal of Production Economics, vol. 129, no. 1, pp. 127-146, 2011.

[52] S. Kirkpatrick, C. D. Gelatt, and M. P. Vecchi, "Optimization by simulated annealing," science, vol. 220, no. 4598, pp. 671-680, 1983.

[53] W. H. Press, S. A. Teukolsky, W. T. Vetterling, and B. P. Flannery, Numerical Recipes 3rd Edition: The Art of Scientific Computing, 3rd ed. New York, NY, USA: Cambridge University Press, 2007. 


\section{BIBLIOGRAPHY OF AUTHORS}

Halil Ibrahim Demir was born in Sivas, Turkey in 1971. In 1988 he received a full scholarship
and entered Bilkent University, Ankara, Turkey, to study in the Industrial Engineering
Department. He got his Bachelor of Science degree in Industrial Engineering in 1993. He then
went to Germany for graduate study, studying German at the intermediate level. In 1994, he
received a full scholarship for graduate study in the USA from the Ministry of Education of
Turkey. In 1997 he received a Master of Science degree in Industrial Engineering from Lehigh
University, Bethlehem, Pennsylvania, USA. He was then accepted to Northeastern University,
Boston, Massachusetts for Ph.D. study. He finished his Ph.D. courses at Northeastern and
completed a Ph.D. thesis at Sakarya University, Turkey in 2005 for a Ph.D. in Industrial
Engineering. He obtained an academic position at Sakarya University as an Assistant Professor.
His Research Areas are Production Planning, Scheduling, Application of OR, Simulation,
Artificial intelligence techniques, Genetic algorithms, Artificial Neural Networks, Fuzzy Logic
and Decision making.

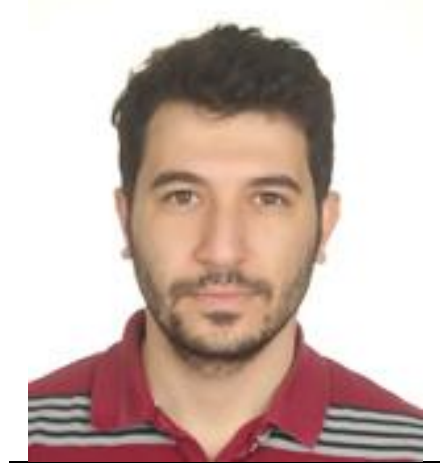

Caner Erden was born in Istanbul in 1989. He received the B.Sc. degree from Istanbul Commerce University in 2006 and M.Sc. degree from Istanbul University in 2013, respectively. He is currently a Ph.D. student and a research assistant in Industrial Engineering Department, Sakarya University. His research interests include genetic algorithms, neural networks, fuzzy sets and rough sets.

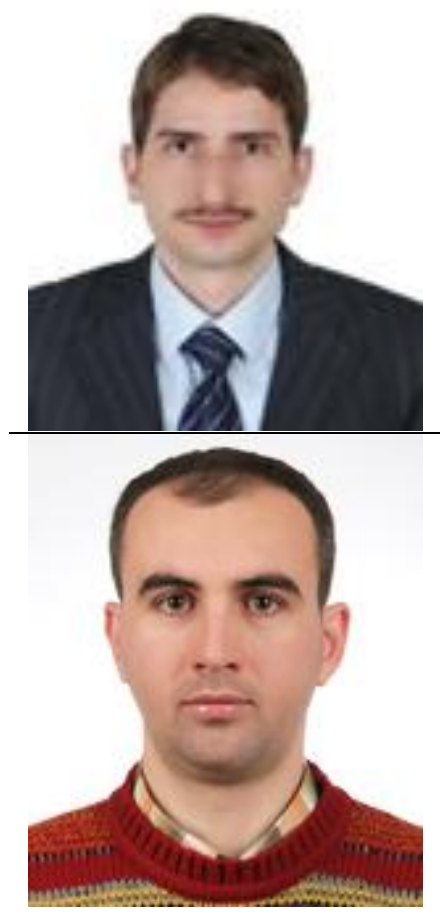

Abdullah Hulusi Kokcam was born in Elazig, Turkey in 1987. He received the BSc degree from Selcuk University Industrial Engineering Department in 2008, and MSc degree from Sakarya University Industrial Engineering Department in 2010. He got his PhD degree from Sakarya University department of Industrial Engineering in 2017. He is currently working as a research assistant at the Sakarya University Industrial Engineering Department. He has been worked on fuzzy project scheduling with meta-heuristic methods in his MSc thesis and an alternative model for assessing school success rate in higher education entrance exam in his $\mathrm{PhD}$ thesis. His research area of interests are project scheduling, meta-heuristic methods, optimization, test measurement, and school performance.

Özer Uygun was born in Sakarya, Turkey in 1976. In 1994 he entered Sakarya University, Turkey to Industrial Engineering Department. He got his Bachelor of Science degree in Industrial Engineering in 1999. He got Master of Science degree in 2002 and Ph.D. degree in 2008 in Industrial Engineering from Sakarya University, Turkey.

He started to his academic position at Marmara University and worked as a Lecturer between 2000 and 2003. Then he worked as a Research Assistant at Sakarya University between 2003 and 2008 and now works as an Associate Professor at this university.

He was a researcher in EU FP6 Network of Excellence (I*PROMS: 2004-2009) and FP6 STREP Project (IWARD: 2007-2009). He has successfully completed the EFQM Assessor Training in Brussels in 2015. His research areas are Multi-criteria decision making, Fuzzy decision making, and Application of Operation research. 